\title{
27 Mechanisms of Acute Liver Failure
}

\author{
Christian TRAutWEIN AND AlEXANDER KOCH
}

\section{KEY POINTS}

- Acute liver failure is characterized by the sudden onset of liver failure in a patient without evidence of chronic liver disease.

- Four different mechanisms are mainly responsible: (1) Infectious (mostly viral), (2) drugs/toxins/chemicals, (3) cardiovascular, and (4) metabolic may trigger acute liver failure

- Viral hepatitis is one of the main causes of acute liver failure. Hepatitis B and non-A/non-C hepatitis are the most frequent forms.

- Suicidal acetaminophen ingestion is the most frequent cause of drug-induced liver failure.

- Three factors determine the prognosis of liver failure: (1) the metabolic consequences resulting from liver failure, (2) the release of mediators and toxic metabolites, and (3) the capacity of the remaining hepatocytes to restore liver mass.

- Clinically, two phases can be differentiated: the mechanisms that trigger liver failure and the clinical manifestations determining the outcome.

- Cerebral edema, infections, and renal failure are important clinical complications limiting the survival of the patients.

- Ammonia levels can be used for risk stratification in patients with acute liver failure and subsequent hepatic encephalopathy.

- Mild hypothermia might improve the outcome of patients with acute liver failure by reducting of intracranial pressure and improving disturbed autoregulation in cerebral blood flow.

- Cytokines are involved in the pathogenesis of acute liver failure as well as in controlling the balance between survival and proliferation of hepatocytes.

\section{INTRODUCTION}

Acute liver failure is characterized by the sudden onset of liver failure in a patient without evidence of chronic liver disease. This definition is important, as it differentiates patients with acute liver failure from patients who suffer from liver failure owing to end-stage chronic liver disease.

From: Liver Immunology: Principles and Practice Edited by: M. E. Gershwin, J. M. Vierling, and M. P. Manns (C) Humana Press Inc., Totowa, NJ
Clinically, patients present with severe liver failure (icterus and coagulation failure) and hepatic encephalopathy. The time between the first symptoms and the manifestation of hepatic encephalopathy has been shown to be crucial for the prognosis of these patients. Therefore several groups have included in their definition the time frame between the onset of symptoms and the start of encephalopathy. The most recent definition uses the term acute liver failure (ALF) as an umbrella and differentiates between three subgroups: hyperacute, acute, and subacute (Table 1). The time between first symptoms and encephalopathy in hyperacute ALF is $7 \mathrm{~d}$, in acute ALF it is 8 to $28 \mathrm{~d}$ and in subacute ALF it is 5 to $26 \mathrm{wk}(1,2)$.

\section{MECHANISMS OF DISEASE}

Different causes may result in ALF. In principal four different classes can be differentiated: (1) infectious (mostly viral), (2) drugs/toxins/chemicals, (3) cardiovascular, and (4) metabolic (3) (Table 2).

There are obvious differences in the mechanisms that initially trigger liver failure. However, at the time of clinical presentation, in most cases a common final stage has been reached in ALF patients. At this stage, three main factors seem important in determining prognosis: (1) the metabolic consequences resulting from the loss of liver cell mass, (2) the release of mediators and toxic metabolites from liver tissue, and (3) the capacity of the remaining vital hepatocytes to restore liver mass $(2,4)$.

Therefore in terms of the mechanisms that are important during ALF, two different phases of acute liver failure can be differentiated: the mechanisms that initially trigger liver failure and those that eventually determine outcome. (Of course this a somewhat artificial differentiation.) In the following discussion, the mechanisms/etiology leading to acute liver failure will be explored first and then the clinical factors influencing outcome.

\section{ETIOLOGY}

\section{INFECTIOUS CAUSES}

Viruses in particular are an essential cause of ALF and, depending on the geographical region, can comprise between 30 and $70 \%$ of all forms of ALF (2-4).

Hepatitis A Virus Only 0.1 to $0.4 \%$ of all infections with the hepatitis A virus (HAV) result in ALF. The proportion 
Table 1

Subgroups of Acute Liver Failure

\begin{tabular}{lc}
\hline & $\begin{array}{c}\text { Time between first symptoms } \\
\text { and start of encephalopathy }\end{array}$ \\
\hline Hyperacute & $<7 \mathrm{~d}$ \\
Acute & $8-28 \mathrm{~d}$ \\
Subacute & $5-26 \mathrm{wk}$ \\
\hline
\end{tabular}

Table 2

Causes of Acute Liver Failure

\begin{tabular}{l}
\hline Infectious (viral) \\
Hepatitis A \\
Hepatitis B \\
Hepatitis C \\
Hepatitis D \\
Hepatitis E \\
Hepatitis non-A/non-B \\
Rare causes \\
Herpes simplex virus \\
Herpes virus type 6 \\
Varicellavirus \\
Cytomegalovirus \\
Epstein-Barr virus \\
Togavirus \\
Paramyxovirus \\
Parainfluenzavirus \\
Drugs/toxins/chemicals \\
Acetaminophen \\
Amanita phalloides \\
Halothane \\
Isoniazid \\
Sodium valoprotate \\
Tetracycline \\
Nonsteroidal anti-inflammatory \\
drugs (NSAIDs) \\
Pirprofen \\
Ketocanazole \\
Cardiovascular \\
Budd-Chiari syndrome \\
Hypotension (circulatory shock) \\
Heart failure (e.g., right ventricular) \\
Hereditary fructose intolerance \\
Malignant tumors \\
Venoocclusive disease \\
Portal vein thrombosis \\
Sepsis \\
Metabolic \\
Wilson's disease \\
Reye's syndrome \\
Acute fatty liver of pregnancy (AFLP) \\
Hemolysis, elevated liver enzymes, \\
\end{tabular}

of patients with ALF is higher in older than in younger patients. This is of relevance, as over the last decades in Western countries HAV infection has occurred more frequently in older patients, and thus the risk of ALF is increased in this population $(5,6)$.

The pathogenesis of HAV-related ALF is not completely understood. Current studies indicate that a combination of a direct cytopathic effect of the virus and immune-mediated mechanisms results in liver destruction.

Hepatitis B Virus The risk of acute liver failure of all patients who are hospitalized because of an acute hepatitis B virus (HBV) infection is around $1 \%$ (7). Thus HBVdepending on the geographical region-is one of the leading causes of ALF.

In general, the virus itself is not cytopathic, but the immune response directed against the virus is essential (8). There are reports that certain viral strains with specific mutations might be important for the occurrence of ALF. However, these reports are mainly from specific cohorts and up to now have had no general implication for HBV-related ALF $(9,10)$.

Frequently at the time of hospitalization the viral load is already decreasing while transaminases are still rising. This may reflect the possibility that different factors contribute to the elimination of the virus. Recent experiments indicate that cytokines - namely, interferon (IFN) - are operating through a noncytopathic mechanism to eliminate the HBV genome in hepatocytes, whereas at a later stage $\mathrm{T}$ cells infiltrate the liver and destroy hepatocytes (11). Therefore activation of HBVspecific $\mathrm{T}$ cells is essential to determine the degree of hepatic injury during ALF.

In the case of $\mathrm{HBV} /$ hepatitis D virus (HDV) coinfection, the risk of ALF is increased (12). The exact mechanisms that lead to more pronounced liver failure have not been defined.

Hepatitis C Virus The risk of ALF through hepatitis C Virus (HCV) is low (2). In Japan in particular cases of HCVrelated ALF have been documented (13). As there are only a few reports in the literature, the pathogenesis of HCV-related ALF is incompletely understood. However, there is evidence that elimination of $\mathrm{HCV}$-specific $\mathrm{T}$ cells is associated with chronic $\mathrm{HCV}$ infection (14). This indicates that the HCV-specific immune response is involved during acute infection and thus is most likely also the determining factor during ALF.

Hepatitis E Virus Acute liver failure owing to hepatitis E Virus (HEV) infection is seldom seen in Western countries. Epidemic outbreaks are known in developing countries including patients with ALF. Pregnant women in particular have a high risk of ALF (up to 20\%) (15). The mechanisms operating in these patients have not yet been studied. Therefore there is no clear hypothesis in the literature, and it is only speculative to draw parallels with HAV.

Rare Cases of Viral Hepatitis In rare cases, different systemic virus infections can present as ALF owing to a predominant manifestation in the liver. These are the herpes simplex virus, herpes virus type 6 , cytomegalovirus, varicella-virus, and Epstein-Barr virus. A few cases have also been described in which an infection with the toga-, paramyxo-, or parainfluenzavirus was documented.

Non-A/Non-B Hepatitis ALF cases often have the characteristics of viral hepatitis. However, in these cases none 
of the known viruses can be diagnosed, and thus these forms have been classified as non-A/non-B hepatitis (2). Non-A/non-B hepatitis is frequently associated with subacute liver failure that has a lower chance of liver restitution.

DRUGS/TOXINS/CHEMICALS Several drugs, chemicals, and toxins can lead to ALF (Table 2), by either direct toxicity or idiosyncratic drug reaction. The most frequent examples are discussed in this review.

Acetaminophen Acetaminophen (Paracetamol, Tylenol) is the most frequent drug leading to ALF. In adults, only higher doses (in general more than 10-12 g) are dangerous, and in most cases, acetaminophen was taken in a suicide attempt. Patients who consume alcohol chronically may be more susceptible induced to acetaminophen, cytochrome $\mathrm{P} 450$ has been induced in their liver.

The pathogenesis of acetaminophen injucy is related to the formation of toxic metabolites through the cytochrome P450 enzymes, especially cytochrome P450 2E1 (16,17). These toxic metabolites are normally conjugated and inactivated through glutathione. However, when glutathione stores are depleted, these toxic metabolites accumulate and result in hepatocyte injury.

A recently published study shows that the measurement of serum acetaminophen-protein adducts can reliably identify acetaminophen toxicity in cases of ALF in which no clinical or historical data are given that would reveal the cause (18).

Mushroom (Amanita) Poisoning Mushroom poisoning, mainly through the species Amanita phalloides, frequently leads to ALF, especially in the Fall. Amanatoxin and phalloidin are the two distinct toxins produced by mushrooms. Phalloidin is not absorbed in the gastrointestinal tract, and the toxic effect of amanatoxin is through inhibition of RNA polymerase II $(3,19)$.

Halothane Halothane is the prototype of an idiosyncratic drug reaction that (less frequently) can also be found after anesthesia with other members of the same family. In general, halothane-related ALF is only found after the second exposure to the drug. Halothane hepatitis is a paradigm for immune-mediated adverse drug reactions. The mechanism appears to be related to development of sensitization to both autoantigens (including CYP2D6) and halothane-altered liver cell determinants (20). Specific antibodies are involved in hepatic injury. These antibodies can only be determined in specialized laboratories.

\section{CARDIOVASCULAR DISORDERS}

Cardiovascular diseases can lead to ALF either by ischemia or by impaired blood flow leaving the liver. Examples of ischemic events are hypotension or heart failure. Stasis of blood flow in the liver may occur owing to malignant tumors, venoocclusive disease, or Budd-Chiari syndrome.

Budd-Chiari Syndrome Classically, Budd-Chiari syndrome is characterized by a symptomatic occlusion of the hepatic veins and is more frequently found in females (21). Depending on the progression of the disease, Budd-Chiari syndrome may result in ALF when sudden closing of all three main liver veins occurs. Typically, acute Budd-Chiari syndrome presents with ascites, abdominal pain, jaundice, and hepatomegaly (22).
Budd-Chiari syndrome is frequently associated with primary myeloproliferative disorders, a factor $\mathrm{V}$ Leiden mutation, anticardiolipin antibodies, and protein $\mathrm{C}$ and $\mathrm{S}$ deficiencies that increase the risk of thrombotic complications (21-23). In general, the course of disease in Budd-Chiari syndrome leads to liver transplantation. Transjugular portosystemic stent shunt (TIPSS) or percutaneous transjugular direct portocaval shunt, in patients with inaccessible hepatic veins, seem to be therapeutic options to decrease the portal pressure gradient, improve synthetic functions, reduce transaminase levels, and control ascites $(24,25)$.

\section{METABOLIC CAUSES}

Different metabolic disorders may present as ALF, for example, Reye's syndrome, which is more common in children; its frequency has declined over the last decades. Also, during pregnancy acute fatty liver of pregnancy (AFLP) or the hemolysis, elevated liver enzymes, and low platelet count (HELLP) syndrome may develop.

Wilson's Disease Wilson's disease is an autosomal recessive genetic disorder. The gene is a copper-transporting P-type ATPase involved in copper transport across cell membranes, with over 200 known mutations in the Wilson gene, although its precise location and function is not known $(26,27)$. In general, patients with ALF owing to Wilson's disease present with only moderately elevated aminotransferases. The patients frequently already have liver cirrhosis and therefore do not fall under the real definition of ALF. However, many of the patients were healthy before onset of the disease and therefore are treated like patients with ALF (28).

There is evidence that elevated copper levels are directly toxic for the cell and involve CD95-mediated apoptosis (29). The current hypothesis postulates that excess copper generates free radicals that deplete cellular stores of glutathione and oxidize lipids, enzymes and cytoskeletal proteins.

\section{MECHANISMS OF ORGAN FAILURE}

As a consequence of ALF, multiorgan failure develops rapidly (Fig. 1). Different factors contribute to multiorgan failure. Frequent problems that occur during this process are cerebral edema and encephalopathy, an impairment of the immune response with a higher rate of infections, coagulation disorders, and cardiovascular and kidney failure; pulmonary and metabolic complications also develop.

\section{ENCEPHALOPATHY AND CEREBRAL EDEMA}

Hepatic encephalopathy is essential for the diagnosis of $\mathrm{ALF}$, it has four different grades, I to IV. (Table 3). In 75 to $80 \%$ of the patients in stage IV, cerebral edema develops independent of the cause of ALF.

The precise pathophysiological mechanisms that lead to hepatic encephalopathy are incompletely understood. However, current studies indicate that the cause is a deficit in neurotransmission rather than a primary deficit in cerebral energy metabolism. Therefore the astrocytes, and the pre- and postsynaptic neurons contribute to the clinical picture (Fig. 2). In contrast, only astrocytes undergo swelling during ALF, and thus determine the degree of cerebral edema $(30,31)$. 


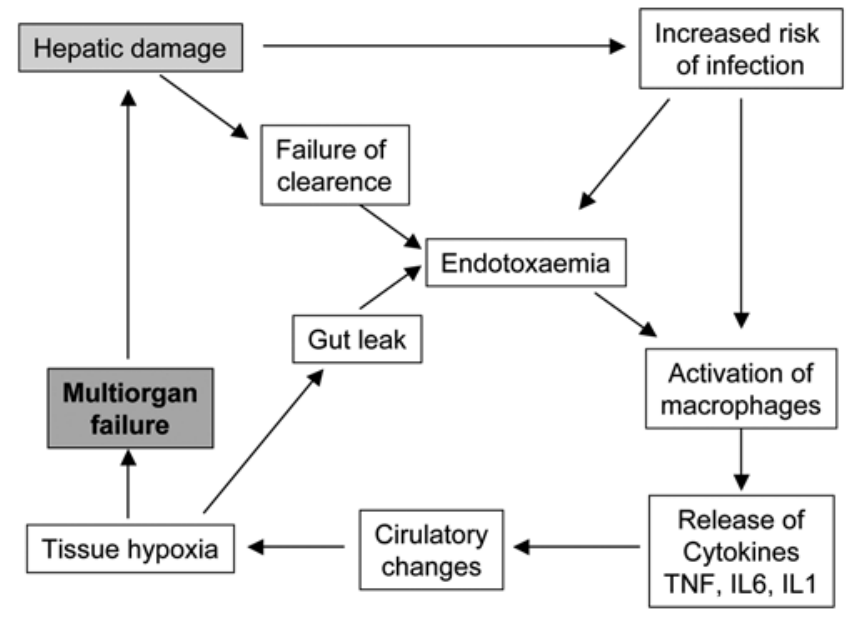

Fig. 1. Mechanisms that contribute to multiorgan failure during acute liver failure.

Table 3

Stages of Acute Hepatic Encephalopathy

\begin{tabular}{lc}
\hline Stage & Mental state \\
\hline I: prodrome & Mild confusion, slurred speech, \\
& slowness of mentation, disordered \\
sleep rhythm, euphoria/depression & Accentuation of stage I; drowsy but \\
speaking; inappropriate & behavior, incontinence \\
II: impending coma & Sleeps most of the time but rousable; \\
III: stupor & incoherent or no speech; marked \\
& confusion \\
IV: coma & Patient may (stage IVA) or may not \\
& (stage IVB) respond to painful \\
& stimuli \\
\hline
\end{tabular}

Modified from ref. 44.

Several factors are discussed in the literature that contribute to hepatic encephalopathy, but ammonia (with a consequent dysregulation of the glutamate neurotransmitter system) seems especially relevant for the development of hepatic encephalopathy and cerebral edema.

Arterial ammonia levels at presentation are predictive of outcome in patients with ALF. Patients with encephalopathy grade III and IV show significantly higher serum ammonia levels than patients with lower grade encephalopathy. Possibly patients with advanced cerebral dysfunction can be determined by a serum ammonia cutoff value of $124 \mu \mathrm{mol} / \mathrm{L}$ or more. Ammonia levels can be used for risk stratification (32).

Ammonia has direct effects on cerebral function by direct and indirect mechanisms (Table 4). There is clear evidence that arterial ammonia concentrations directly correlate with cerebral edema and thus herniation (33). Experimental evidence also demonstrates that physiological ammonia concentrations
Table 4

\section{Effects of Ammonia on Brain Function}

Electrophysiological effects of the ammonium ion

Effects on the inhibitory postsynaptic potential

Effects on glutamatergic neurotransmission

Effects on brain energy metabolism

Inhibition of $\alpha$-ketoglutarate dehydrogenase

Effects on astrocyte function

Decreased expression of the glutamate transporter GLT-1

Increased expression of "peripheral-type" benzodiazepine receptors

Alzheimer type II astrocytosis

Effects on the glutamate neurotransmitter system

Direct postsynaptic effects

Impaired neuron-astrocytic trafficking of glutamate

Inhibition of glutamate uptake

Altered glutamate receptors

Effects mediated by formation of glutamine in brain

Cytotoxic brain edema

Increased uptake of aromatic amino acids

Other effects

Stimulation of L-arginine uptake and neuronal nitric oxide synthase (nNOS) expression

Data from ref. 31 .

alone result in astrocyte swelling. Most likely a metabolite of ammonia rather than ammonia itself is the important mediator of astrocyte swelling. Additionally, higher glutamine concentrations are a consequence during this process, and they accelerate cerebral edema $(30,31)$.

Higher ammonia concentrations have a direct effect on the glutamate neurotransmitter system. Glutamate is the major excitatory neurotransmitter in the mammalian brain (Fig. 2). After release at the presynaptic neuron, glutamate binds to glutamate receptors on the postsynaptic neuron (NMDA) or on both the postsynaptic neuron and astrocytes (AMPA/KA). Additionally, glutamate transporters on astrocytes (GLT-1 and GLAST) and neurons (EAAC1) limit the expression of glutamate in the neuronal cleft. After uptake of glutamate in astrocytes via GLT-1, it is transformed into glutamine. Ammonia downregulates GLT-1 expression on astrocytes, and this results in higher and prolonged extracellular glutamate concentrations in patients with ALF. Additionally, there is evidence that the glutamate receptors are differentially expressed during ALF and thus dysregulation of the glutamate system is one of the important determinants for hepatic encephalopathy during ALF (30,31).

Other neurotransmitters that contribute to hepatic encephalopathy are GABA, serotonin, and the opioid system.

A few uncontrolled studies (34-36) show a protective effect of mild hypothermia in ALF and cerebral edema. Hypothermia $\left(32-35^{\circ} \mathrm{C}\right)$ can be safely and easily applied. The risk of complications (arrhythmias, myocardial ischemia, infections, coagulopathy) increases with the degree and duration of hypothermia, mainly with body temperatures below $32^{\circ} \mathrm{C}$. Hypothermia reduces intracranial pressure and reestablishes disturbed autoregulation of cerebral blood flow. Some studies 


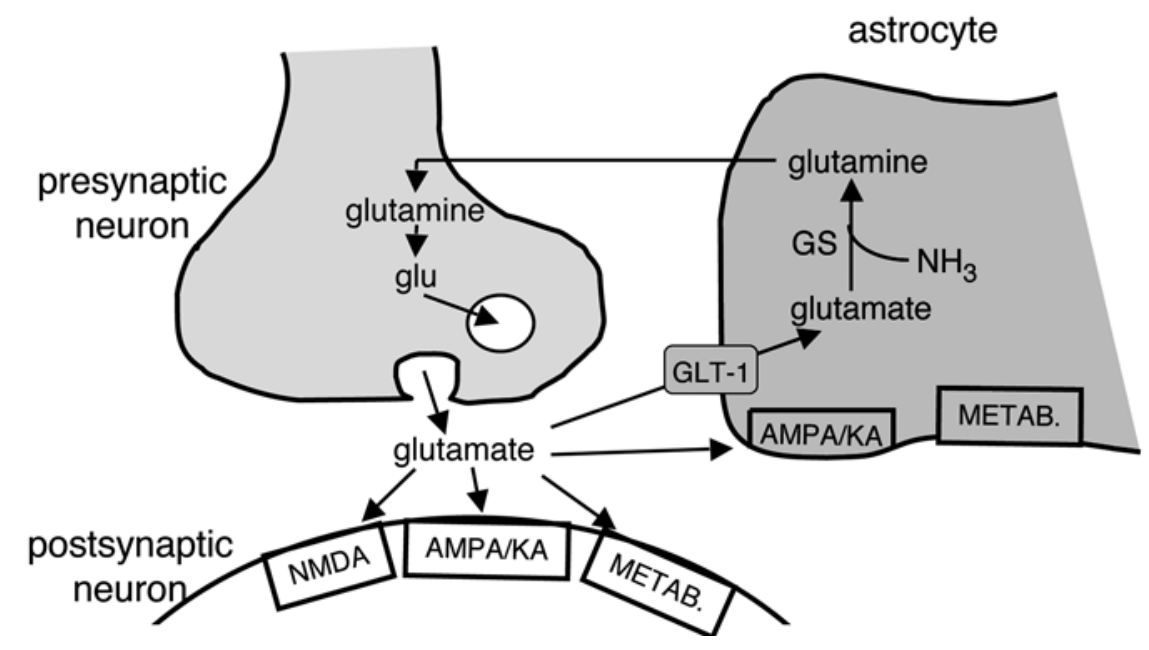

Fig. 2. The role of glutamate/glutamine in the brain. Shown are the localizations of the glutamate transporter (GLT-1) and glutamate receptor subtypes (NMDA, AMPA/KA, METAB) on astrocytes and neurons involved in glutamatergic neurotransmission. Glu, glutamate. (Modified from ref. 31.)

suggest that hypothermia can reduce the extent of liver injury in ALF (37), in contrast, hypothermia might also lead to impaired liver regeneration. Further research and controlled clinical studies are required to clarify the significance of hypothermia in ALF.

\section{CARDIOVASCULAR DYSFUNCTION}

Patients with ALF are characterized by hypotension and tachycardia. The basis for this observation is vasodilation in the periphery that results in relative hypovolemia, hypotension, and high output failure. Factors that contribute to this regulation are capillary leakage, low osmotic pressure, and sepsis.

Some patients with ALF may suffer from hypertension. This problem may arise especially in patients with hepatic encephalopathy grade IV and typically occurs when cerebral edema is evolving.

\section{INFECTION}

Infection and thus sepsis is a major problem in patients with ALF. Patients with a long stay in the ICU have a very high risk in particular, and this may actually be the ultimate reason for death (38). Studies from the King's Collage Hospital group clearly indicated that monitoring by daily cultures (sputum, urine, blood) identifies bacteria in up to $90 \%$ and fungal infections in around $30 \%$ of these patients $(39,40)$. Frequently the classical signs (fever, leukocytosis, biochemical parameters like C-reactive protein and procalcitonin) in patients with ALF are not directly correlated with infection or are absent. The sites of the body with the most common infections are the lung, urinary tract, and blood (Fig. 3). If antibiotic or antifungal treatment is necessary in these patients, the potential for further liver injury caused by antibiotic drugs should be considered.

Besides the increased risk of patients being managed in an ICU, additional factors contribute to the higher risk of infections in patients with ALF, namely, defects in the immunological defense mechanisms (complement, Kupffer cell function, polymorphonuclear cell function, cell-mediated immune response). The liver is the main source of complement (e.g., $\mathrm{C} 3$ and C5) production. As a consequence of lower complement levels, activity of polymorphonuclear leukocytes and complement-mediated opsonization is reduced. Therefore phagocytosis and killing of polymorphonuclear cells is inhibited in ALF patients. Through the portal circulation bacterial toxins are regularly brought to the liver tissue that are cleared by the resident Kupffer cells of the liver. In ALF there is a correlation between hepatic damage and Kupffer cell dysfunction. Additionally, Kupffer cells are a major source of cytokines, and their dysregulation also contributes to the impaired immune response. Defective lymphocyte function has been attributed to impaired interleukin-2 (IL-2) production in these patients. Thus the defect in immune response can be explained on different levels of the immune system $(3,39)$.

\section{PULMONARY COMPLICATIONS}

Pulmonary complications are frequent (41). Different mechanisms contribute to this observation. Up to $50 \%$ of the patients have infections, especially after intubation and subsequent mechanical ventilation (Fig. 3) (42). The possible consequent capillary leakage can result in an ARDS-like syndrome that is further augmented by the often required infusion of albumin, fresh-frozen plasma, and coagulation factors.

Besides these local mechanisms systemic causes, as a result of liver failure, also lead to intrapulmonary vasodilation and pulmonary edema, which further increase the risk of hypoxic complications (43).

\section{RENAL FAILURE}

Renal failure with oligo- and anuria is found in 40 to $50 \%$ of patients with ALF $(44,45)$. In acetaminophen and Amanita poisoning, a direct toxic effect additionally contributes to kidney failure. Therefore, in these patients the rate of kidney failure is increased to $70 \%$. 


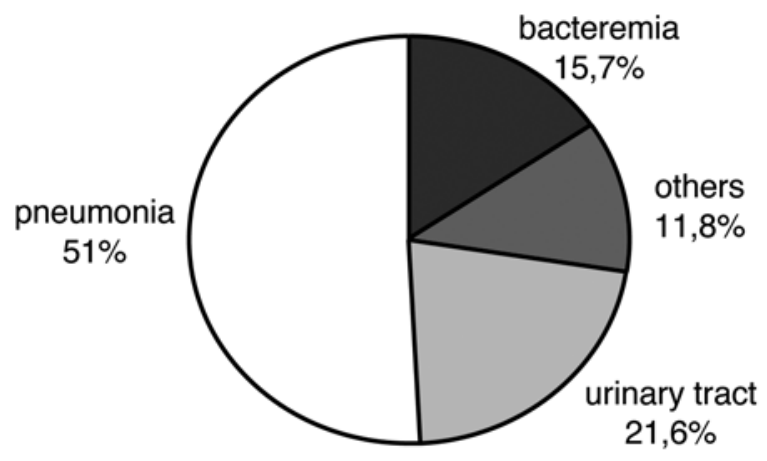

Fig. 3. Sites of infections during acute liver failure. (from ref. 39.)

The association of liver failure and kidney failure is functional and is known as the hepatorenal syndrome. The syndrome is characterized by contraction of the vessels with distinctively reduced renal perfusion. At this stage the kidney impairment is completely reversible. In the further course of the disease, at a more advanced stage, hepatorenal syndrome may progress to tubulus necrosis, which is not reversible (44).

Additional severe complications in patients with hepatorenal syndrome such as long periods of hypotension or sepsis have a fatal effect on kidney function and significantly reduce the prognosis of patients with fulminant hepatic failure.

\section{METABOLIC COMPLICATIONS}

The liver is essential for several metabolic functions. Two particular problems are frequent in patients with ALF: hypoglycemia and acid-base disturbances.

Different mechanisms lead to hypoglycemia during ALF. The damaged liver loses its capacity to mobilize glycogen stores and to perform gluconeogenesis. Additionally, the liver is the major site of insulin metabolism, and the consequently reduced disintegration of insulin results in elevated insulin serum levels. All three mechanisms contribute to hypoglycemia, and this may also aggravate mental status. In terms of treatment, it might be important to differentiate between hypoglycemia and hepatic encephalopathy as possible causes for disturbed mental status at certain stages.

Both acidosis and alkalosis may be present. Metabolic alkalosis is most frequent, as urea synthesis in the liver is impaired, which results in the accumulation of the two precursor substrates bicarbonate and ammonium. Alkalosis is associated with hypokalemia, which is further aggravated by high sodium reabsorption in patients with ALF.

Acidosis is found in up to $30 \%$ of patients with acetaminophen-dependent ALF. In patients with a different etiology acidosis is evident in only 5\%. In which lactate acidosis is present because of tissue hypoxia owing to a disturbed microcirculation and the inability of the injured liver tissue to metabolize lactate.

\section{COAGULATION DISORDERS}

Because of the central role of the liver in coagulation and thrombolysis, severe coagulation disorders are a major problem in ALF. As a result of reduced coagulation factors and a deficit of inhibitors of fibrinolysis, the hemostasis situation in ALF is complex $(46,47)$.

Factors I, II, V, VII, IX, and X are synthesized in the liver. Therefore prothrombin time is a useful parameter-besides the measurement of single factors - to assess the lack of production of coagulation factors. An additional factor that may contribute to the decrease in blood coagulation factors is disseminated intravasal coagulation (DIC), which may be associated with sepsis during ALF.

Antithrombin III (AT-III) is also synthesized in the liver and is thus reduced. The decrease in AT-III concentration further contributes to coagulation problems.

The number of blood platelets is frequently decreased, and additionally the function and morphology of blood platelets are impaired. Together, these changes result in adhesion abnormalities, leading to decreased aggregation and increased adhesion.

\section{DYSREGULATION OF THE CYTOKINE NETWORK IN ACUTE LIVER FAILURE}

In recent years it has become obvious that there is a dysregulation of cytokine expression during ALF in humans. For example, it has been shown that mediators of the acute phase response-IL-6 and tumor necrosis factor (TNF) - are strongly elevated in the liver and serum of ALF patients. The meaning of this observation becomes more evident through the development of animal models where by the role of each molecule can be more clearly defined. As there is evidence that several cytokines might be involved in the pathogenesis of ALF, all the different aspects can not be covered in this review. We found here on two cytokines, TNF and IL-6 and review recent data in this field.

\section{IL-6/GP130-DEPENDENT SIGNALS}

IL-6 interacts on the cell surface with the IL-6 receptor (gp80). This complex associates with two gp130 molecules, which results in activation of Janus kinases and in turn in phosphorylation of tyrosines at the intracellular part of gp130. After tyrosine phosphorylation, the ras/map kinase pathways and transcription factors Stat 1 and-3 become activated (Fig. 4) (48). In hepatocytes, IL-6 is one of the main inducers of the acute-phase response, and in recent years it has become evident that IL-6 also contributes to the regulation of additional pathophysiological conditions in the liver (49-51).

One of the simplest models for studying the loss of liver tissue is the removal of two-thirds of the liver by surgical resection (52). This model has been applied mainly in rodents (e.g., rat and mouse), and after 1 to 2 wk liver tissue has been restored by hepatocyte proliferation. In recent years it has become obvious that IL-6 and TNF are involved in the restoration of liver mass (53). The ultimate proof of this hypothesis was the observation that liver regeneration was impaired in IL-6 and TNF receptor 1 (TNF-RI) knockout mice after two-thirds hepatectomy. The defect in regeneration in both knockout strains could be restored through IL-6 stimulation $(54,55)$. The current model of how IL-6 and TNF 

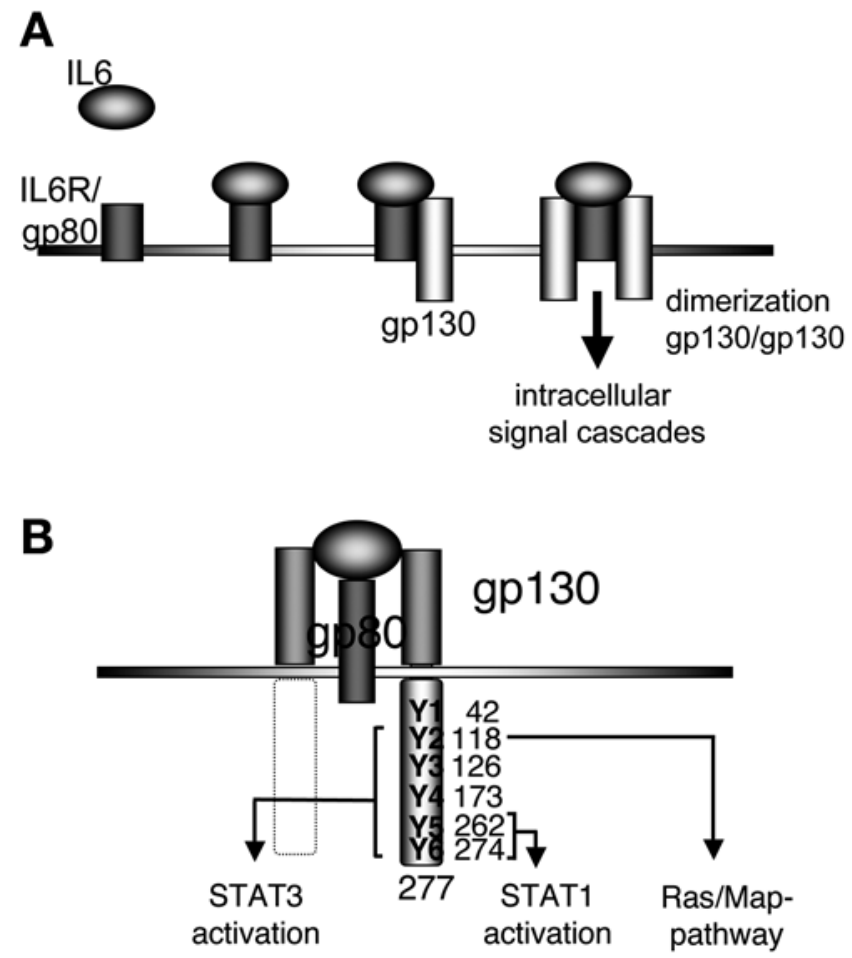

Fig. 4. Interleukin-6 (IL-6)/gp130-dependent signaling. (A) On the cell membrane IL-6 first interacts with the gp80/IL-6 receptor (IL-6R). This complex interacts with gp130 molecules that dimerize and induce intracellular signaling cascades. (B) gp130 dimerization results in the activation of Janus kinases that phosphorylate distinct tyrosines (Y) at the intracellular part of the gp130 receptor. Phosphorylation of the second tyrosine is essential for activation of the Ras/Map pathway. Phosphorylation of the four distal tyrosines results in Stat3 activation; the two most distal tyrosines can also activate Stat1.

may work in concert during liver regeneration after partial hepatectomy is shown in Fig. 5.

The role of IL-6-dependent signals in liver regeneration was further analyzed in more detail using conditional gp130 knockout mice. In these mice the gp130 receptor-the common signal transducer of all IL-6 family members - was deleted in the liver. After hepatectomy, these mice had only an impairment of liver regeneration when the animals were also stimulated with lipopolysaccharide (LPS) after hepatectomy (56). Therefore these experiments demonstrate that IL-6 activates protective pathways in hepatocytes that are important to guarantee liver regeneration but that have no direct impact on the cell cycle progression of hepatocytes.

In humans suffering from ALF, IL-6 serum levels are highly elevated, and in the liver infiltrating cells express tremendous (10-fold higher compared with controls) amounts of IL-6 (49,50,57). In animal models of ALF, IL-6 serum levels are also greatly increased (58), and treatment with an hyper-IL-6 designer molecule reduces liver cell damage in several animal models $(59,60)$. Therefore not only during liver regeneration after partial hepatectomy, but also during ALF it is obvious that IL-6 plays a protective role for hepatocytes; cDNA arrays

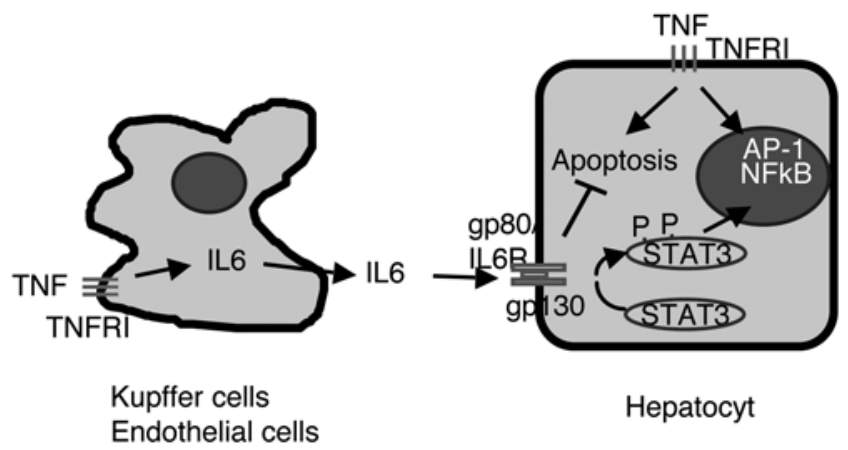

Fig. 5. Role of interleukin-6 (IL-6) and tumor necrosis factor (TNF) during liver regeneration. Activation of IL-6-and TNF-dependent pathways in nonparenchymal (Kupffer and endothelial cells) and parenchymal (hepatocytes) during liver regeneration after partial hepatectomy is shown.

further demonstrate that IL-6 activates antiapoptotic pathways, e.g., Bcl-xl in hepatocytes $(61,62)$.

In recent experiments our group generated a hepatocytespecific knockout mouse for gp130. These animals show normal embryonal development. After IL-6 and also after LPS stimulation, regulation of the acute-phase response is completely blocked. After LPS injection the hepatocyte-specific gp130 knockout mouse shows a phenotype with a strong increase in transaminases in the serum and apoptosis in the liver (49-51).

In summary, all the IL- 6 data in animal models show that gp130-dependent pathways in hepatocytes activate protective mechanisms, and in humans it is also likely that IL-6 renders hepatocytes more resistant. Therefore it might be promising to modulate IL-6/gp130-dependent pathways in humans during ALF as a potential therapeutic approach.

\section{TNF-DEPENDENT PATHWAYS}

TNF belongs to a family of several known of Fas and TNF receptor apoptosis-inducing ligands (TRAIL). There is also evidence for an involvement in the pathogenesis of fulminant hepatic failure. At present the role of TNF has been studied in more detail in both human and animal models.

TNF binds to two receptors, TNF-R1 and TNF-R2, on the cell surface. After ligand binding, the intracellular domains of the receptors interact with adapter molecules that activate different pathways (Fig. 6). In the case of TNF-R1, first the molecule TNF-R-associated death domain (TRADD) and then additional molecules bind that activate the caspase cascade either via Fas-associated death domain (FADD) or via TNF-associated factor/ receptor-interacting protein (TRAF/RIP) jun kinase

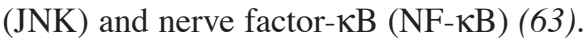

In practically all the current animal models, TNF seems to be involved in the pathogenesis of ALF. In humans it has also been shown that TNF serum levels correlate with prognosis in ALF patients (57). In animal models, blocking experiments using anti-TNF attenuates liver failure, and therefore it is obvious that TNF plays a central role in the pathogenesis of ALF. 

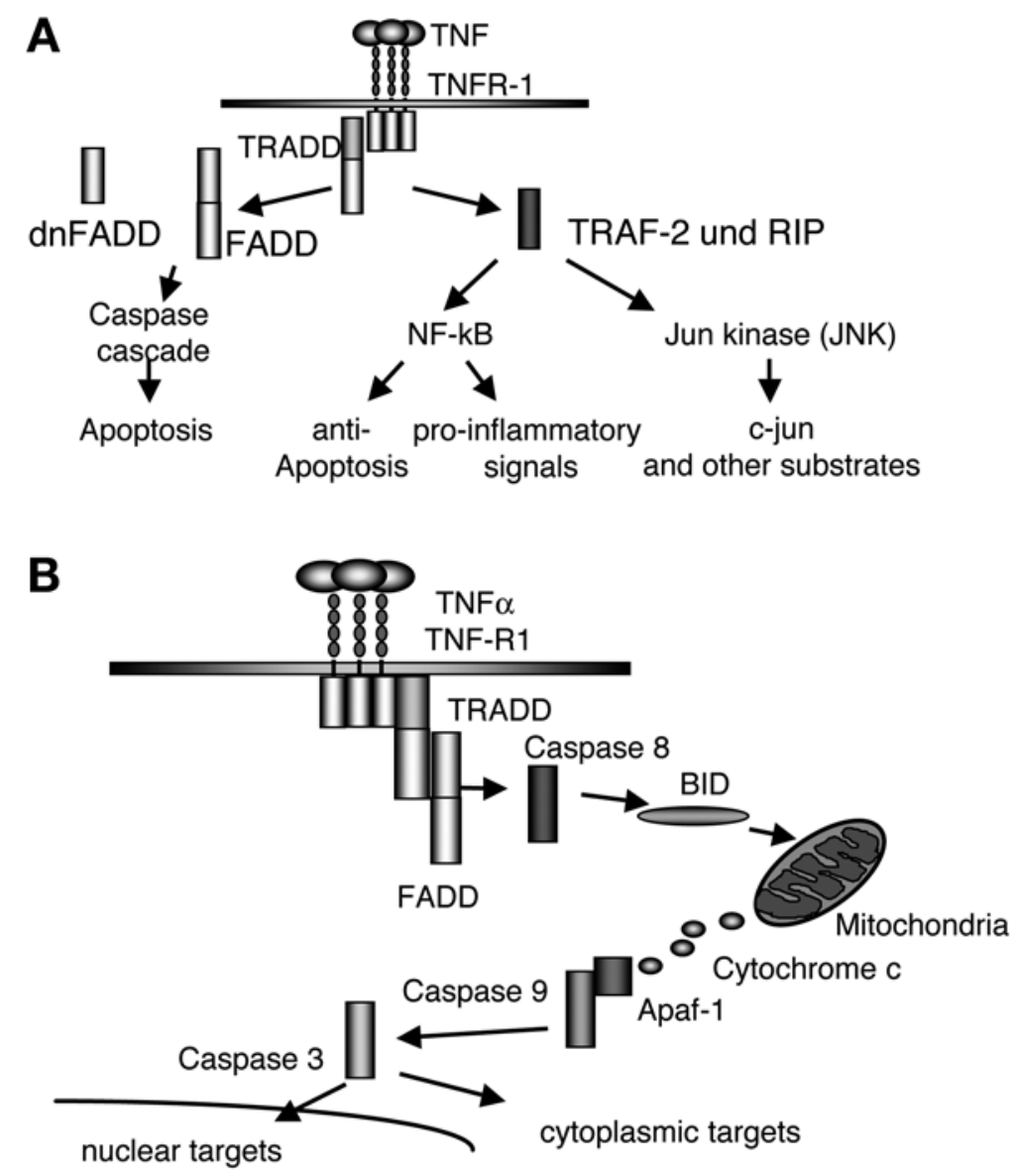

Fig. 6. Tumor necrosis factor (TNF)/TNF receptor 1 (TNF-R1)-dependent signaling. (A) The molecules and pathways that are involved in TNF/TNF-R1-dependent signaling are depicted. Activation of the specific intracellular TNF-dependent pathways in the cell has different effects as indicated. (B) The caspase cascade, resulting in apoptosis of the cell is shown in more detail. Activation of caspase 8 via Fas-associated dealth domain (FADD) triggers a cascade of events including cytochrome c release from mitochondria that results in caspase 3 activation and apoptosis of hepatocytes.

However, further studies indicated that TNF does not have a uniform role in the different models. Depending on the model, the TNF-dependent effect might be related to a different cell in the liver or another intracellular pathway. Three models of acute liver failure and the role of TNF will be discussed.

Endotoxin/Galactosamine Model During LPS/galac to samine (GaIN)-induced liver injury, TNF induces the transcription of several proinflammatory genes, e.g., chemokines, nitric oxide, and adhesion molecules like intracelluler adhesion molecule-1 (ICAM-1), vascular cell adhensive molecule-1 (VCAM-1), and P-selectin (64-66). These changes in the liver are essential to trigger the extravasation of neutrophils into the liver parenchyma, which results in cytotoxic liver cell damage. During this scenario a stepwise cascade has been described consisting of three events: (1) sequestration of neutrophils in the liver vasculature (2) transendothelial migration, and (3) adherence-dependent cytotoxicity against hepatocytes (67).

Therefore, in the LPS/GalN model, TNF obviously triggers an inflammatory mechanism mediated via NF-KB that results in liver cell damage. In this model, parenchymal as well as nonparenchymal cells are involved in this process.

Galactosamine/TNF Model Administration of GalN and TNF triggers apoptosis of hepatocytes in vivo and in vitro. The essential role of TNF-R1 in this model has been demonstrated by TNF-R1 knockout mice that are resistant to TNF/GalN treatment (68). GaIN will directly inhibit transcription and thus synthesis of antiapoptotic signals. Therefore, in this model the FADD-dependent pathway leading to apoptosis is the essential step in ultimately inducing liver cell damage. In contrast, the NF-KB and JNK pathway does not seem to be involved in the pathogenesis of liver damage, and also nonparenchymal cells play no role. In this model, simple administration of an adenoviral construct expressing a dominant molecule blocking the FADD pathway is protective (57). These data indicate that the caspase cascade activated by TNF might be a relevant target during ALF.

Concanavalin A Model Concanavalin A (ConA) is a leptin with high affinity to the hepatic sinus (69). Accumulation of ConA in the hepatic sinus results in activation of liver natural 
killer T (NKT) cells, i.e., NK1.1 CD4+/CD8- T-Cell recepter (TCR) $\alpha \beta^{+}$, and NK1.CD4 ${ }^{-} / \mathrm{CD}^{-} \mathrm{TCR}^{-} \beta^{+}$, which are essential to trigger the early phase of ConA-induced liver injury $(70,71)$. Consecutively CD4-positive and polymorphonuclear cells are attracted to the hepatic sinus and trigger an increase of cytokines like TNF, IL-2, IFN- $\gamma$ IL-6, granulocyte macrophage colony-stimulation factor (GM-CSF) and IL-1 (58). TNF- $\alpha$ and IFN- $\gamma$ have direct implications for the induction of liver cell injury, as anti-TNF- $\alpha$ and anti-IFN- $\gamma$ antibodies protect from ConA-induced liver injury $(72,73)$ and $\mathrm{IFN}^{-/-}$and $\mathrm{TNF}^{-/-}$ mice are resistant to ConA induced liver cell damage.

Until now a stepwise process of liver damage, as shown for the endotoxin/LPS model, could not be defined for the ConA model. Adhesion molecules like ICAM-1 or VCAM-1 seem to play a minor role. Mice pretreated with antibodies against both adhesion molecules or ICAM-1 knockout mice still undergo liver cell injury (74).

The role of TNF-dependent pathways has been further studied in this model using adenoviral vector expression of the inhibitor- $\kappa \mathrm{B}(\mathrm{I}-\kappa \mathrm{B})$ superrepressor or the dominant negative FADD molecule. Neither constructs has an impact on the degree of ConA-induced liver injury, indicating that NF- $\mathrm{KB}$ dependent targets and the FADD-dependent caspase cascade in hepatocytes are of minor relevance in this model. In contrast, there is a close correlation of TNF-dependent JNK activation with ConA-induced liver injury (49-51). Additionally, first results using an JNK inhibitor indicate that ConA-induced liver injury can be inhibited. Therefore the current data indicate that in the ConA model TNF-dependent JNK activation is essential to trigger liver cell injury.

Translation of TNF-Dependent Pathway Results in Animal Models Into Therapeutic Approaches in Humans The current data in animal models and humans indicate that TNF plays an essential role in the pathogenesis of ALF. However, as demonstrated for the three animals models discussed-depending on the pathogenesis - the intracellular pathways that are activated by TNF could have opposing effects. Therefore, at present it is too early to translate the results into humans, and potential therapeutic approaches cannot be deduced, as it is unclear which of the TNF-dependent pathways are involved in triggering liver failure in individual patients.

\section{CONCLUDING REMARKS AND OPEN QUESTIONS}

ALF is characterized by sudden onset in patients without evidence of chronic liver disease, by which ALF is differentiated from end-stage chronic liver disease. According to the time between first symptoms and encephalopathy, ALF is divided into three subgroups: hyperacute, acute, and subacute. The prognosis of ALF patients is determined by the metabolic situation resulting from the loss of liver cell mass, the release of mediators and toxic metabolites from injured liver tissue, and the capacity of remaining vital hepatocytes to restore functional liver mass.

Suicidal acetaminophen ingestion is the most frequent cause of drug-induced liver failure worldwide, with approx 500 deaths a year in the United States. Other important mechanisms are viral hepatitis (e.g., hepatitis B and non-A/non-C hepatitis), and cardiovascular and metabolic disorders.

ALF leads to multiorgan failure, especially cerebral edema and encephalopathy. Owing to the diminished liver function, higher rates of infections and coagulation disorders are observed. Cerebral edema, infections, and renal failure are important clinical complications limiting the survival. For risk stratification in patients with ALF and subsequent hepatic encephalopathy, serum ammonia levels can be used. Advanced cerebral dysfunction is expected at serum ammonia levels of $124 \mu \mathrm{mol} / \mathrm{L}$ or higher.

Cardiovascular dysfunction is characterized by peripheral vasodilation that results in relative hypovolemia, hypotension, and high output failure. Capillary leakage and high-volume therapy can lead to an ARDS-like syndrome and cause hypoxic complications.

Prothrombin time is a useful parameter to assess the extent of remaining liver function.

Intensive care therapy is crucial for patients with ALF to manage multiorgan failure, and mild hypothermia to reduce cerebral edema should be considered. Further research and controlled clinical studies are needed to evaluate the importance of hypothermia.

\section{REFERENCES}

1. O'Grady JG, Schalm SW, Williams R. Acute liver failure: redefining the syndromes. Lancet 1993; 342:273-275.

2. Williams R. Classification, etiology, and considerations of outcome in acute liver failure. Semin Liver Dis 1996; 16:343-348.

3. Sussman NL. Fulminant hepatic failure. In: Zakim D, Boyer T, eds. A Textbook of Liver Disease, Mc Graw-Hill, york. 1996; $618-650$.

4. Losser MR, Payen D. Mechanisms of liver damage. Semin Liver Dis 1996; 16:357-367.

5. Fagan EA, Williams R. Fulminant viral hepatitis. Br Med Bull 1990; 46:462-480.

6. Masada CT, Shaw BW Jr, Zetterman RK, Kaufman SS, Markin RS. Fulminant hepatic failure with massive necrosis as a result of hepatitis A infection. J Clin Gastroenterol 1993; 17:158-162.

7. Hoofnagle JH, Carithers RL Jr, Shapiro C, Ascher N. Fulminant hepatic failure: summary of a workshop. Hepatology 1995; 21: 240-252.

8. Chisari FV. Rous-Whipple Award Lecture. Viruses, immunity, and cancer: lessons from hepatitis B. Am J Pathol 2000; 156: $1117-1132$.

9. Liang TJ, Hasegawa K, Rimon N, Wands JR, Ben-Porath E. A hepatitis $\mathrm{B}$ virus mutant associated with an epidemic of fulminant hepatitis. N Engl J Med 1991; 324:1705-1709.

10. Stuyver L, De Gendt S, Cadranel JF, et al. Three cases of severe subfulminant hepatitis in heart-transplanted patients after nosocomial transmission of a mutant hepatitis B virus. Hepatology 1999; 29: 1876-1883.

11. Guidotti LG, Rochford R, Chung J, Shapiro M, Purcell R, Chisari FV. Viral clearance without destruction of infected cells during acute HBV infection. Science 1999; 284:825-829.

12. Mendez L, Reddy KR, Di Prima RA, Jeffers LJ, Schiff ER. Fulminant hepatic failure due to acute hepatitis B and delta coinfection: probable bloodborne transmission associated with a springloaded fingerstick device. Am J Gastroenterol 1991; 86:895-897.

13. Yoshiba $M$, Dehara $K$, Inoue $K$, Okamoto $H$, Mayumi $M$. Contribution of hepatitis $\mathrm{C}$ virus to non-A, non-B fulminant hepatitis in Japan. Hepatology 1994; 19:829-835. 
14. Gruener NH, Lechner F, Jung MC, et al. Sustained dysfunction of antiviral CD8+ T lymphocytes after infection with hepatitis $\mathrm{C}$ virus. J Virol 2001; 75:5550-5558.

15. Hamid SS, Jafri SM, Khan H, Shah H, Abbas Z, Fields H. Fulminant hepatic failure in pregnant women: acute fatty liver or acute viral hepatitis? J Hepatol 1996; 25:20-27.

16. Whitcomb DC, Block GD. Association of acetaminophen hepatotoxicity with fasting and ethanol use. JAMA 1994; 272: $1845-1850$.

17. Makin AJ, Williams R. Acetaminophen-induced hepatotoxicity: predisposing factors and treatments. Adv Intern Med 1997; 42: 453-483.

18. Davern T, James L, Hinson J, Polson J, Larson M, et al. Measurement of serum acetaminophen-protein adducts in patients with acute liver failure. Gastroenterology 2006; 130:687-694.

19. Shakil AO, Mazariegos GV, Kramer DJ. Fulminant hepatic failure. Surg Clin North Am 1999; 79:77-108.

20. Neuberger J. Halothane hepatitis. Eur J Gastroenterol Hepatol 1998; 10:631-633.

21. Okuda K, Kage M, Shrestha SM. Proposal of a new nomenclature for BuddChiari syndrome: hepatic vein thrombosis versus thrombosis of the inferior vena cava at its hepatic portion. Hepatology 1998; 28:1191-1198.

22. Faust TW. Budd-Chiari Syndrome. Curr Treat Options Gastroenterol 1999; 2:491-504

23. Deltenre P, Denninger MH, Hillaire S, et al. Factor V Leiden related BuddChiari syndrome. Gut 2001; 48:264-268.

24. Khuroo MS, Al-Suhabani H, Al-Sebayel M, et al .Budd-Chiari syndrome: longterm effect on outcome with transjugular intrahepatic portosystemic shunt. J Gastroenterol Hepatol. 2005; 20:1494-1502

25. Quateen A, Pech M, Berg T, et al. Percutaneous transjugular direct porto-caval shunt in patients with Budd-Chiari syndrome. Cardiovasc Intervent Radiol 2006; 29(4):565-570.

26. Mercer JF. The molecular basis of copper-transport diseases. Trends Mol Med 2001; 7:64-69.

27. Thomas GR, Forbes JR, Roberts EA, Walshe JM, Cox DW. The Wilson disease gene: spectrum of mutations and their consequences. Nat Genet 1995; 9:210-217.

28. Gow PJ, Smallwood RA, Angus PW, Smith AL, Wall AJ, Sewell RB. Diagnosis of Wilson's disease: an experience over three decades. Gut 2000; 46:415-419.

29. Strand S, Hofmann WJ, Grambihler A, et al. Hepatic failure and liver cell damage in acute Wilson's disease involve CD95 (APO-1/Fas) mediated apoptosis. Nat Med 1998; 4:588-593.

30. Butterworth RF. Hepatic encephalopathy and brain edema in acute hepatic failure: does glutamate play a role? Hepatology 1997; 25:1032-1034.

31. Hazell AS, Butterworth RF. Hepatic encephalopathy: An update of pathophysiologic mechanisms. Proc Soc Exp Biol Med 1999; 222:99-112.

32. Bhatia V, Singh R, Acharya SK. Predictive value of arterial ammonia for complications and outcome in acute liver failure. Gut 2006; 55:98-104.

33. Clemmesen JO, Larsen FS, Kondrup J, Hansen BA, Ott P. Cerebral herniation in patients with acute liver failure is correlated with arterial ammonia concentration. Hepatology 1999; 29:648-653.

34. Jalan R, Olde Damink SW, Deutz NE, Hayes PC, Lee A. Restoration of cerebral blood flow autoregulation and reactivity to carbon dioxide in acute liver failure by moderate hypothermia. Hepatology 2001; 34:50-54.

35. Jalan R, Olde Damink SW, Deutz NE, et al. Moderate hypothermia prevents cerebral hyperemia and increase in intracranial pressure in patients undergoing liver transplantation for acute liver failure. Transplantation 2003; 75:2034-2039.

36. Roberts DR, Manas D. Induced hypothermia in the management of cerebral oedema secondary to fulminate liver failure. Clin Transplant 1999; 13:545-547.
37. Fu T, Blei AT, Takamura N, et al. Hypothermia inhibits Fas-mediated apoptosis of primary mouse hepatocytes in culture. Cell Transplant 2004; 13:667-676.

38. Rolando N, Wade J, Davalos M, Wendon J, Philpott-Howard J, Williams R. The systemic inflammatory response syndrome in acute liver failure. Hepatology 2000; 32:734-739.

39. Rolando N, Philpott-Howard J, Williams R. Bacterial and fungal infection in acute liver failure. Semin Liver Dis 1996; 16:389-402.

40. Wade JJ, Rolando N, Hayllar K, Philpott-Howard J, Casewell MW, Williams R. Bacterial and fungal infections after liver transplantation: an analysis of 284 patients. Hepatology 1995; 21:1328-1336.

41. Trewby PN, Warren R, Contini S, et al. Incidence and pathophysiology of pulmonary edema in fulminant hepatic failure. Gastroenterology 1978; 74:859-865.

42. Rolando N, Harvey F, Brahm J, et al. Prospective study of bacterial infection in acute liver failure: an analysis of fifty patients. Hepatology 1990; 11:49-53.

43. Williams A, Trewby P, Williams R, Reid L. Structural alterations to the pulmonary circulation in fulminant hepatic failure. Thorax 1979; 34:447-453.

44. Sussman NL, Lake JR. Treatment of hepatic failure-1996: current concepts and progress toward liver dialysis. Am J Kidney Dis 1996; 27:605-621.

45. Wong F, Blendis L. Hepatorenal failure. Clin Liver Dis 2000; 4:169-189.

46. Izumi S, Langley PG, Wendon J, et al. Coagulation factor V levels as a prognostic indicator in fulminant hepatic failure. Hepatology 1996; 23:1507-1511.

47. Lee WM. Management of acute liver failure. Semin Liver Dis 1996; 16:369-378.

48. Heinrich PC, Behrmann I, Muller-Newen G, Schaper F, Graeve L. Interleukin6-type cytokine signalling through the gp130/Jak/STAT pathway. Biochem J 1998; 334:297-314.

49. Streetz K, Fregien B, Plumpe J, et al. Dissection of the intracellular pathways in hepatocytes suggests a role for Jun kinase and IFN regulatory factor-1 in Con A-induced liver failure. J Immunol 2001; 167:514-523.

50. Streetz KL, Wustefeld T, Klein C, Manns MP, Trautwein C. Mediators of inflammation and acute phase response in the liver. Cell Mol Biol (Noisy-leGrand) 2001; 47:661-673.

51. Streetz KL, Wustefeld T, Graw A, et al. The role of gp130 during acute-phasereaction and liver injury. Hepatology 2001; 34:278A.

52. Higgins GM, Anderson RM. Experimental pathology of liver. I. Restoration of liver of white rat following partial surgical removal. Arch Pathol 1931; 12:186-202.

53. Trautwein C, Rakemann T, Niehof M, Rose-John S, Manns MP. Acutephase response factor, increased binding, and target gene transcription during liver regeneration. Gastroenterology 1996; 110:1854-1862.

54. Cressman DE, Greenbaum LE, DeAngelis RA, et al. Liver failure and defective hepatocyte regeneration in interleukin-6- deficient mice. Science 1996; 274:1379-1383.

55. Yamada Y, Kirillova I, Peschon JJ, Fausto N. Initiation of liver growth by tumor necrosis factor: deficient liver regeneration in mice lacking type I tumor necrosis factor receptor. Proc Natl Acad Sci USA 1997; 94:1441-1446.

56. Wuestefeld T, Klein C, Streetz KL, et al. gp130-dependent pathways are essential in regulating the priming phase and acute phase response after partial hepatectomy. Hepatology 2001; 34:386A.

57. Streetz K, Leifeld L, Grundmann D, et al. Tumor necrosis factor alpha in the pathogenesis of human and murine fulminant hepatic failure. Gastroenterology 2000; 119:446-460.

58. Trautwein C, Rakemann T, Malek NP, Plumpe J, Tiegs G, Manns MP. Concanavalin A-induced liver injury triggers hepatocyte proliferation. J Clin Invest 1998; 101:1960-1969.

59. Hecht N, Pappo O, Shouval D, Rose-John S, Galun E, Axelrod JH. Hyper-IL-6 gene therapy reverses fulminant hepatic failure. Mol Ther 2001; 3:683-687. 
60. Galun E, Zeira E, Pappo O, Peters M, Rose-John S. Liver regeneration induced by a designer human IL-6/sIL-6R fusion protein reverses severe hepatocellular injury. FASEB J 2000; 14:1979-1987.

61. Kovalovich K, Li W, DeAngelis R, Greenbaum LE, Ciliberto G, Taub R. Interleukin-6 protects against Fas-mediated death by establishing a critical level of anti-apoptotic hepatic proteins FLIP, Bcl-2, and BclxL. J Biol Chem 2001; 276:26,605-26,613.

62. Li W, Liang X, Leu JI, Kovalovich K, Ciliberto G, Taub R. Global changes in interleukin-6-dependent gene expression patterns in mouse livers after partial hepatectomy. Hepatology 2001; 33 : 1377-1386.

63. Bradham CA, Plumpe J, Manns MP, Brenner DA, Trautwein C. Mechanisms of hepatic toxicity. I. TNF-induced liver injury. Am J Physiol 1998; 275:G387-G392.

64. Essani NA, Bajt ML, Farhood A, Vonderfecht SL, Jaeschke H. Transcriptional activation of vascular cell adhesion molecule- 1 gene in vivo and its role in the pathophysiology of neutrophil-induced liver injury in murine endotoxin shock. J Immunol 1997; 158: 5941-5948.

65. Jaeschke H, Smith CW, Clemens MG, Ganey PE, Roth RA. Mechanisms of inflammatory liver injury: adhesion molecules and cytotoxicity of neutrophils. Toxicol Appl Pharmacol 1996; 139: 213-226.

66. Xu H, Gonzalo JA, St Pierre Y, et al. Leukocytosis and resistance to septic shock in intercellular adhesion molecule 1-deficient mice. J Exp Med 1994; 180:95-109.
67. Jaeschke H, Essani NA, Fisher MA, Vonderfecht SL, Farhood A, Smith CW. Release of soluble intercellular adhesion molecule 1 into bile and serum in murine endotoxin shock. Hepatology 1996; 23:530-536.

68. Leist M, Gantner F, Jilg S, Wendel A. Activation of the $55 \mathrm{kDa}$ TNF receptor is necessary and sufficient for TNF-induced liver failure, hepatocyte apoptosis, and nitrite release. J Immunol 1995; 154:1307-1316.

69. Tiegs G, Hentschel J, Wendel A. A T cell-dependent experimental liver injury in mice inducible by concanavalin A. J Clin Invest 1992; 90:196-203.

70. Takeda K, Hayakawa Y, Van Kaer L, Matsuda H, Yagita H, Okumura K. Critical contribution of liver natural killer T cells to a murine model of hepatitis. Proc Natl Acad Sci USA 2000; 97:5498-5503.

71. Kaneko Y, Harada M, Kawano T, et al. Augmentation of Valpha14 NKT cellmediated cytotoxicity by interleukin 4 in an autocrine mechanism resulting in the development of concanavalin A-induced hepatitis. J Exp Med 2000; 191:105-114.

72. Gantner F, Leist M, Lohse AW, Germann PG, Tiegs G. Concanavalin Ainduced T-cell-mediated hepatic injury in mice: the role of tumor necrosis factor. Hepatology 1995; 21:190-198.

73. Kusters S, Gantner F, Kunstle G, Tiegs G. Interferon gamma plays a critical role in T cell-dependent liver injury in mice initiated by concanavalin A. Gastroenterology 1996; 111:462-471.

74. Wolf D, Hallmann R, Sass G, et al. TNF-alpha-induced expression of adhesion molecules in the liver is under the control of TNFR1relevance for concanavalin A-induced hepatitis. J Immunol 2001; 166:1300-1307. 